How do reviews from professional critics interact with other signals of product quality? Evidence from the video game industry

(Short title: Interaction of Professional Critic Reviews) 


\title{
How do reviews from professional critics interact with other signals of product quality? Evidence from the video game industry
}

\begin{abstract}
Experience goods are characterized by information asymmetry and a lack of ex ante knowledge of product quality, such that reliable external signals of quality are likely to be highly valued. Two potentially credible sources of such information are reviews from professional critics and 'word-of-mouth' from other consumers. This paper makes a direct comparison between the relative influences and interactions of reviews from both of these sources on the sales performance of video games software. In order to empirically estimate and separate the effects of the two signals, we analyze a sample of 1,480 video games and their sales figures between 2004 and 2010. We find evidence to suggest that, even after taking steps to control for endogeneity, reviews from professional critics have a significantly positive influence on sales which outweighs that from consumer reviews. We also find evidence to suggest that reviews from professional critics also interact significantly with other signals of product quality. Consequently, we contend that professional critics adopt the role of an influencer, whereas word-of-mouth opinion acts more as a predictor of sales in the market for video games.
\end{abstract}

Key words : Signaling theory; Information asymmetry; Critics; Word-of-mouth; Video games 


\section{How do reviews from professional critics interact with other signals of product quality? Evidence from the video game industry}

\section{Introduction}

Experience goods are characterized by a lack of a priori knowledge of product quality, leading to information asymmetry between consumers and producers (Nelson 1970). An effective means by which to reduce this asymmetry is the transmission of credible signals of quality to the consumer. Whereas the traditional signaling model $^{1}$ involves the transmission of signals from agents directly to principals, it may be that signals originating from external third-parties have a stronger and more reliable status than the signals of producers due to the independence of the source. In the context of entertainment markets, there exists a well-developed body of literature on the effect of signaling on sales performance, particularly with respect to the motion picture industry. Such studies typically find a positive correlation between film reviews and box office returns as a result of reduced information asymmetry (Basuroy et al., 2003; Boatwright et al., 2007). However, despite a growing body of evidence suggesting that these external signals might influence buyer behavior when considered separately, few authors have previously attempted to simultaneously analyze the influence of these two signals on sales performance, nor any possible interaction between these two signals; especially in contexts outside of the movie industry.

In this study, we focus on the relationship between commercial performance and two observable signals of product quality; reviews from professional critics and online word-of-mouth. In the case of the latter, we use online consumer reviews as a proxy; an approach with is consistent with other studies by Wien and Olsen (2012) and Racherla et al. (2012). The analysis of consumer behavior and sales performance in the video game industry we undertake in this study makes a unique contribution to the literature by offering a direct comparison between the relative influences of consumer word-of-mouth with reviews from professional critics. Such a comparison is potentially valuable given the prevailing view that word-of-

\footnotetext{
${ }^{1}$ Signaling theory was firstly introduced by Michael Spence in his seminal 1973 article about the reduction of asymmetry information in the selection of potential job candidates. In the Spence model, candidates' education levels serve as a signal of the quality of future employees. Potential employers interpret the education signal and adjust their selection behavior in response to the education levels by offering a better job proposal than if they had not been given the signal by the candidates.
} 
mouth and other content generated by users is becoming an increasingly influential factor in consumer decision making; possibly even to the exclusion of traditional reliance on the opinions of experts or professional critics (Holbrook \& Addis, 2007; Bughin et al., 2010). Our analysis explicitly considers the possibility that these signals affect consumer behavior both jointly and separately through undertaking a more detailed examination of interactions between signals and the subsequent effect on sales performance. Accordingly, the paper aims to address the following specific research questions:

(i) How do signals of quality from professional critics influence buyer behavior compared with consumer word-of-mouth?

(ii) How do these signals interact; both with each other and with a range of alternative indicators of product quality?

Our extensive empirical analysis shows that when reviews from professional critics and consumer wordof-mouth are controlled for simultaneously, the valence of consumer word-of-mouth does not significantly affect sales performance. Instead, we find evidence of a significant relationship with respect to reviews from professional critics even after taking steps to control for endogeneity through the use of a GMM estimation. We also demonstrate the importance of interaction between reviews from professional critics and other external signals of product quality that might influence consumer behavior. Our study is the first to apply such techniques in the context of the market for video games and builds on a mounting recognition of the need to control for reviews from both professional critics and consumer word-ofmouth when modelling sales performance (Basuroy et al., 2014)

The following section presents background information on the video games industry, an entertainment market has received significantly less attention in the academic literature compared to the movie industry. This is followed by a section where we outline our research hypotheses and subsequently move on to provide a description of our data. Finally, we present our empirical results, followed by a discussion of the findings and managerial implications.

\section{The video games market}

From its origins in the 1970s up to its meteoric rise in significance and profitability during the last decade, 
the home video gaming market has traditionally involved competition between firms under conditions of classic oligopoly. The high fixed and low marginal costs of production as well as strong network externalities has led to a series of fierce contests between hardware manufacturers to establish dominant platforms. Well-known examples include Atari and Mattel's battle during the 1980s, superseded by the rivalry between Nintendo and Sega in the early 1990s and Microsoft and Sony in the early 2000s. As a consequence, the competition to develop recognizable software franchises and 'killer apps' that sell hardware units and build a strong installed user base has led to the establishment of established gaming franchises such as Mario, Grand Theft Auto and Call of Duty; many of which have become cultural icons appealing to a wider range of consumers. Indeed, while gaming may originally have been seen to be the exclusive preserve of children and teenagers, the market has evolved and matured along with its original consumers while continuing to welcome a succession of new generations and demographics. According to the Entertainment Software Association (2012), the average gamer in the US is now thirty years of age, while forty-seven per cent of gamers are female. In fact, adult female gamers now represent around twice the proportion of gamers made up by boys aged seventeen or younger.

[Figure 1 about here]

Figure 1 illustrates both the upward trend and cyclical performance of the US video games market from 1995 to the present day, measured in terms of hardware and software sales revenues. In 2012, it can be seen that the market was valued at around $\$ 15 \mathrm{bn}$ annually. Historically, there is a clear pattern of significant growth during and immediately following years where new hardware models are launched, followed by flattening or declining performance in subsequent years. For reference, the significant years where this occurred are 1995/6 (release of the Sony Playstation and Nintendo 64), 2000/01 (release of Playstation 2, Nintendo Gamecube and Microsoft Xbox) and 2005/06 (release of the Microsoft Xbox 360, Nintendo Wii and Sony Playstation 3). Despite the huge successes observed over the last decade, the market experienced a relative decline from 2008 to 2012, possibly due to a combination of weak economic conditions, the rise in popularity of gaming on mobile phones and tablets and the approach of the end of the generational cycle. The decline in sales have resulted in some recent high-profile casualties, most notably the demise of major games publisher THQ.

Due to high development costs and uncertain market demand, it is vitally important for video games developers and publishers to be able to forecast product sales efficiently, in particular those of new products at the beginning of their product life cycles. Thus, it is essential to understand the signals that are 
relevant to the purchase decision and how the information contained in these signals can be measured and evaluated in order to optimize managerial decisions and strengthen competitive advantages. However, despite this obvious need for research into the behavior of video games consumers, only a very limited number of studies investigate the relationship between external signals of quality and sales performance in this particular market context. Of those which do, Cox (2014) finds that reviews from professional critics are an important determinant of sales performance, while Zhu and Zhang (2010) show that online reviews are more influential for less popular games and for those consumers that are more experienced in their use of the internet. However, there generally remains a shortage of empirical studies of sales performance in the market for video games, especially when compared with other entertainment goods such as motion pictures. Our study at least partly addresses this shortfall.

The following section outlines the variety of signals that are likely to influence consumer behavior in the market for video games software, based both on signaling theory and empirical evidence from the related literature. Through due consideration of the nature of these signals, we develop a number of explicit research hypotheses that form the basis of the empirical investigation presented later in this paper.

\section{Research hypotheses}

\section{The influence of individual signals}

A number of studies have estimated the impact of reviews on the sales performance of entertainment goods; both from professional critics (Prag and Casvant, 1994; Gemser et al., 2007; Basuroy and Chaterjee, 2008; Terry et al., 2011; Hennig-Thurau et al., 2012) and consumer word-of-mouth (Dellarocas, 2003; Godes and Mayzlin, 2004; Senecal and Nantel, 2004; Chevalier and Mayzlin, 2006; Dellarocas et al., 2007; Chen and Xie, 2008; Archak et al., 2011; Cui et al. 2012). However, a major limitation of many of these studies is that they tend to control for only one of these types of product review, even though Chintagunta et al. (2010) has highlighted the potentially significant differences between reviews from professional critics and users; such as reviews from professional critics being quotable in marketing and promotional material (Basuroy et al. 2011). If this is indeed the case, it would be valuable and perhaps even necessary to control for both sources of information in order to compare and contrast any influence on consumer behavior.

Additionally, while a majority of studies highlight the significance of the valence of online reviews upon sales performance, a selection of others have investigated a number of different aspects of online reviews besides the raw assessment of product quality. For example, Duan et al. (2008) find that it is actually the 
volume of consumer reviews that associates more strongly with commercial performance compared to other measures, while Clemons et al. (2006) find that it is the consistency of online ratings which offers the most significant predictor of sales growth among the craft beer industry. Other studies (e.g. Liu, 2006 and Schindler and Bickart, 2012) examine the length of reviews and find these to be positively correlated to perceived value.

Based on the findings of these studies, we contend that independent information expressed in product reviews has three plausible ways in which it can influence consumer behavior. First, more positive evaluations lower uncertainty over product quality among prospective consumers. Second, if evaluations reach near unanimity in opinion, then customers' certainty in their purchase decision will increase. Third, the more reviews have been submitted, the lower is the evaluation insecurity among future buyers. Consequently, we formulate the following research hypothesis referring to professional critics and consumer word-of-mouth:

$\mathrm{H}_{1}$ : The valence, volume and consistency of product reviews from both professional critics and consumer word-of-mouth will have a positive significant effect on total sales.

\section{The interaction of signals}

A majority of studies of the entertainment industry typically concentrate on the separate evaluation of distinct types of signals as part of a multiple regression analysis. However, it is likely in reality that consumers assess credibility and reliability of the interaction of distinct types and similar types of signals jointly. Although there is a shortage of studies in marketing on the interaction of signals, the economics literature has produced a number of studies on the value of multiple signals of product quality, most notably in relation to the moral hazard associated with agency theory (Hölmstrom, 1979) and most often considered in relation to issues of corporate governance and performance-related pay (Fama, 1980; Jensen \& Murphy, 1990; Fahlenbrach \& Stulz, 2011). However, it is also possible that the effect of additional signals diminishes at the margin as the total number of available signals increases. In the specific context of entertainment markets, Basuroy et al. (2006) are one of the first to empirically study interaction between signals of quality. Using movie business industry data and a dynamic simultaneous-equations model, they show that the interaction of greater advertising expenditures and sequels has a significant positive interaction effect on box office revenues. Other authors such as Kirmani and Rao (2000) and Dhar et al. (2012) also account for interaction between limited numbers and types of independent signals in their 
theoretical framework. Building on this work and the principles of signaling theory, we consider the importance of additional signals and their interactions and propose the following additional research hypotheses:

$\mathrm{H}_{2}$ : The interaction between reviews from professional critics and consumer word-of-mouth and will positively affect total sales.

$\mathrm{H}_{3}$ : The interaction between product reviews and a range of additional observable signals of product quality (sequels, re-releases, mature age rating) will positively affect total sales.

Thus, $\mathrm{H}_{2}$ allows us to test the extent to which reviews from professional critics interact with word-ofmouth and whether consumers ultimately place a higher value on unanimity between the two sources of information. Correspondingly, $\mathrm{H}_{3}$ allows us to test the extent to which a number of signals of product quality are interpreted individually or jointly by consumers in this particular market context.

\section{Data and Method}

In order to empirically verify the influence of critic reviews on market success, we construct a sample consisting of 1,304 video games and their commercial performance between 2004 and 2010. Sales figures are obtained from VGChartz, while other characteristics (genre, age rating etc.) are obtained from the MobyGames database. We concentrate our analysis on the five mainstream console and handheld devices available during this period: Nintendo DS, Nintendo Wii, Sony PlayStation 3, Sony PSP and Xbox 360. Product reviews are obtained from Metacritic, a website that reviews music, movies, TV shows and especially video games on the basis of a weighted average of mainstream critical responses. Metacritic is widely acknowledged and highly regarded source of review information among consumers and within the industry itself, with video game publishers even beginning to be explicitly refer to the site in their contracts with development studios and imposing penalties if a title is reviewed poorly (Wingfield, 2007). We record the reported 'metascores' from professional critics, as well as those from consumer reviews as a proxy for online word-of-mouth. The approach of using online reviews as a proxy in this way is consistent with a number of prior studies of cinema box office performance using reviews from Yahoo Movies (Liu, 2006; Chintagunta et al., 2010) and IMDb (Roschk \& Große, 2013) for such purposes. Indeed, very recent 
studies, such as Hennig-Thurau et al. (2014), have even begun to use comments shared using microblogging sites such as Twitter as a proxy for consumer word-of-mouth in a similar way.

A summary of key descriptive statistics for variables used in the empirical analysis can be found in Table 1. As stated in our hypothesis section, we test the effect of three different factors relating to reviews to model the influence of both professional critics and word-of-mouth on sales performance; valence, volume and consistency. Valence represents a comparable measure of weighted average review scores from professional critics and consumers ${ }^{2}$. According to the data in Table 1 valence levels appear to be relatively similar for both groups, with individual titles achieving an average review score of approximately 70/100. In addition, we also measure the volume or total number of reviews posted on Metacritic, with the expectation that greater numbers of total reviews lead to reduced levels of uncertainty among consumers. On average, consumers generate more than twice the quantity of individual reviews compared to professional critics, with an average of around 38 critic reviews per title versus an average of around 95 reviews posted by consumers.

[Table 1 about here]

The final aspect of reviews we measure in this study is the consistency of ratings awarded by critics and users. Alongside the overall scores awarded, Metacritic also reports the numbers of positive, mixed and negative reviews posted for each title. We postulate that higher levels of inconsistency will lead to greater uncertainty of product quality among consumers, while near-unanimous verdicts will lead to reductions in uncertainty. Our measure of consistency is the sum of squares of the proportions of positive, negative, and mixed opinions among the total number of reviews. Accordingly, the consistency variable is somewhat analogous to the Hirschman-Herfindahl index, which captures the degree of homogeneity or heterogeneity of any variable of interest (usually market concentration). Our consistency variable is therefore bounded between an upper value of 1 (perfect consistency) and a lower value of 0.33 (exactly equal proportions of reviews in each of the three opinion categories). By way of offering an additional insight into the consistency of product reviews, Figure 2 presents Lorenz curves for both consistency measures and shows that word-of-mouth reviews tend to demonstrate greater unanimity compared to those of professional critics; a condition that is also verified by the means of our measure of consistency ( 0.65 for professional

\footnotetext{
${ }^{2}$ Metacritic measures user valence on scale ranging from 0-10 (with decimals), while scores from professional critics are measured on a scale ranging from 0-100 (without decimals). In order to allow for direct comparability between the two measures, we simply rescale the user scores to make them directly comparable to scores from professional critics by multiplying through by a factor of 10 .
} 
critics and 0.69 for word-of-mouth). Nonetheless, both curves are fairly close to the $45^{\circ}$ line, which suggests that there generally tends to be a high level of unanimity in the review of video games from both sources.

[Figure 2 about here]

Owing to the use of similar variables capturing online reviews from both professional critics and users, we present correlation coefficients between these variables in Table 2 below. The highest level of correlation can be observed between the valence of users and professional critics, with a coefficient of +0.63 . Although this relatively high correlation is potentially a cause for concern, the Variance Inflation Factor (VIF) scores reported later in our regression analysis show that the inclusion of both user and professional critic valence in the same model specification leads to an acceptable level of inflation of the coefficient estimates compared to a situation where there is no linear relationship between predictor variables. The highest VIF values in any of our regression specifications do not exceed a value of 7 and are well below the threshold whereby multicollinarity would significantly affect our results. Nonetheless, we use only centered values for all of our measures of professional critic response and word-of mouth in order to minimize multicollinarity once interaction terms are introduced into the model.

[Table 2 about here]

In addition to the above, we also include a number of additional signals of product quality, such as dummy variables indicating whether the title is a sequel or re-release, reflecting reputation effects and prior market success for a particular franchise. Rereleases account for around $6 \%$ and sequels around $56 \%$ of the titles in our sample. In particular, it should be noted that this represents a significantly larger proportion of sequels than is typically seen in studies of other cultural and creative industries such as Basuroy et al. (2006). Additionally, as per DeVany and Walls (2002) and Ravid (1999), we utilize an age-classification variable by including the variable Rating $M$ (mature age rating) in our analysis, which applies to around $18 \%$ of the titles in our sample. Besides testing for the influence of critics and additional signaling effects, we also control for gameplay characteristics, release information and other available ex ante indicators of quality, publisher size and market share. Our list of control variables is consistent with those used in similar studies of the movie industry, such as Litman (1983), Sochay (1994) and Elberse and Eliashberg (2003). We also control for genre and group effects, as well as miscellaneous industry and time (life-cycle) effects through the inclusion of a linear trend measuring the length of time in years between the release of each individual 
title and the relevant hardware platform. The full list of model variables included in the regression explaining sales performance for title $i$ is therefore;

$$
\begin{aligned}
\ln \left(\text { Sales }_{i}\right)=\alpha & \beta_{1} \text { Critic Valence }_{i}+\beta_{2} \text { Critic Volume }_{i}+\beta_{3} \text { Critic Consistency }_{i}+\gamma_{1} \text { User Valence }_{i} \\
& +\gamma_{2} \text { User Volume }_{i}+\gamma_{3} \text { User Consistency }_{i}+\rho_{1}\left(\text { Critic Valence }_{i} \times \text { User Valence }_{i}\right) \\
& +\theta_{1}\left(\text { Critic Valence }_{i} \times \text { Other Signals }_{i}\right)+\theta_{2}\left(\text { User Valence }_{i} \times \text { Other Signals }_{i}\right) \\
& +\sigma_{1} \text { Other Signals }_{i}+\eta_{1} \text { Game Specific Controls }_{i}+\eta_{2} \text { Gameplay Perspective Controls }_{i} \\
& +\eta_{3} \text { Hardware Platform Controls }_{i}+\eta_{4} \text { Genre Controls }_{i} \\
& +\eta_{5} \text { Major Publisher Controls }_{i}+\varepsilon_{i}
\end{aligned}
$$

Where the definitions of each of these individual or vectors of variables are consistent with the categories of variables reported in Table 1. In particular, note that the 'Other Signals' vector consists of controls for whether title $i$ is a sequel, re-release or has a mature age rating, while the 'Game Specific Controls' vector consists of controls for time (life cycle), maximum number of players supported, online functionality, licensed franchise, coming packaged with an accessory and availability on other hardware platforms. Specifically, the values of the $\beta$ and $\gamma$ coefficients allow us to test hypothesis $\mathrm{H}_{1}$, the $\rho$ coefficient allows for the testing of $\mathrm{H}_{2}$ and the $\theta$ coefficients allow for the testing of $\mathrm{H}_{3}$. The following section presents the results of this and a series of alternate model specifications as a robustness check and as a means by which to explore a range of different interactions of signals both separately and jointly.

\section{Results}

Table 3 summarizes the estimations of the relationship between sales and reviews from professional critics and users. Regression output from seven different model specifications are presented including a variety of combinations of explanatory variables outlined in the full model outlined above in Equation (1). Models I-III estimate the relationship between sales and a range of alternative combinations of critical and wordof-mouth response, thereby directly testing hypotheses $\mathrm{H}_{1}$. Model IV includes a variable to measure interaction between professional critic and user valence, which allows for the testing of hypothesis $\mathrm{H}_{2}$. Finally, models V-VII include additional interaction terms to capture the interrelationships between valence and a range of other external signals of product quality, which allows for the testing of $\mathrm{H}_{3}$. The regression output is remarkably consistent between model specifications, indicating that our findings are broadly robust. However, some important distinctions can be made, most notably between the specifications that do and do not include the various combinations of interaction terms. 
Focusing on the model specifications that do not include interaction terms (I-III), it is apparent that every measure of professional critical response (valence, volume and consistency) associates positively and significantly with sales. A one unit increase in valence, which is equivalent to a $1 \%$ increase in the review score, is found to associate with an increase in unit sales of around 1.5\% on average. Comparatively, each additional review from a professional critic associates with an average increase in sales of around 1.6\%, while a one unit increase in the consistency of reviews posted by professional critic's associates with an average increase in unit sales of around $113 \%{ }^{3}$. When taken in isolation, the equivalent independent variables representing the response of word-of-mouth look relatively similar. A one unit increase in the average word-of-mouth review increases unit sales by around $1.4 \%$, while the association with volume of word-of-mouth reviews is around $0.1 \%$ increase in sales for each additional review. This indicates that the marginal impact of an additional review from professional critics is significantly greater than that of a single additional user review, such that volume of critic reviews seems to be a more important determinant of sales performance than the volume of consumer reviews.

Perhaps contrary to expectations, a statistically significant negative relationship is observed between the consistency of word-of-mouth reviews and unit sales, with an elasticity of approximately -0.54 . As we also see this negative association demonstrated via the negative correlation coefficient reported in Table 2, the only reasonable interpretation for this finding is that a lack of consistency in consumer word-of-mouth does not seem to have a limiting effect on product sales. In fact, this result may simply suggest that consumers tend to be more consistent in their assessment of poorly selling games, whereas successful titles tend to split consumer opinion to a greater extent. Broadly speaking, this may suggest that consumers tend to act as predictors rather than influencers in this particular market context. It is also worth noting that these coefficient estimates for volume and consistency of ratings from both professional critics and consumer word-of-mouth remain consistent across all of the model specifications that we subsequently present, leading us to conclude that these findings are considerably robust.

When the reviews from professional critics and word-of-mouth reviews are considered together in model III, a somewhat different pattern emerges to that presented above. The estimated elasticity of sales with respect to the valence of professional critic reviews is relatively unchanged, while the elasticity of sales to

\footnotetext{
${ }^{3}$ As this variable is bounded between $0-1$ the 'elasticity' is best regarded as approximately +1.13 .
} 
word-of-mouth reviews is found to be statistically equivalent to zero. These results suggest that the influence of professional critical response on sales dominates that of word-of-mouth if both are controlled for simultaneously, while coefficient estimates reflecting the relationship between sales and the volume and consistency of reviews from both users and professional critics do not dramatically change. Overall, these findings offer limited support for hypothesis $\mathrm{H}_{1}$, given that unit sales are found to be relatively elastic to all measures of professional critical response and both the volume and consistency of word-of-mouth. However, as the effect of user valence becomes statistically equivalent to zero once critic valence is controlled for, we conclude that word-of-mouth does not seem to associate with any significant variation in commercial performance. This finding is further reinforced by the results from model specification IV, where an additional term is included to capture the interaction between the valence of professional critics and users, which also shows that the coefficient attached to professional critic valence remains positive and significant. By contrast, the estimated coefficients for valence of users and the interaction term are both statistically indistinguishable from zero, leading us to reject hypothesis $\mathrm{H}_{2}$. This essentially suggests that it is the opinion of professional critics that dominates the valence of users when explaining variation in sales; user valence is found to have no significant relationship either when controlled for independently or in interaction with the opinions of professional critics.

It should also be noted that in all of our model specifications, the effect of two other credible ex ante signals of quality (whether the respective title is a sequel and/or a re-release) are found to significantly increase unit sales, with the average of the coefficient estimates suggesting average increases in unit sales of around $23 \%$ and $25 \%$ respectively. This indicates that familiarity with an existing franchise acts as a strong signal of product quality that influences buyer behavior. The final quality signal we use (an 'M' or 'Mature' age rating) is not found to significantly affect unit sales in these specifications. It is also important to highlight that our control for original selling price leads to a positive and statistically significant estimate of the price-elasticity of demand. Although the relationship between price and sales is found to be relatively inelastic (estimates place the elasticity between +0.24 and +0.39 ), the consistently positive sign obviously contradicts theoretical expectations. It is possible that price is correlated with some other unobserved variable such as the anticipated duration or depth of gameplay experience, or that price itself is regarded as a credible signal of quality in this market context. Alternatively, it may simply be that video game publishers price titles in accordance with anticipated demand; consumers are simply willing to pay higher prices for 'blockbuster' titles. Whatever the cause, we do not suggest that demand for video games increases with price ceteris paribus, but instead highlight the coefficient estimates as potentially signifying the issues of omitted variable bias and/or endogeneity that we are unable to account for in the regression 
framework without additional instruments.

Models VI and VII include interaction terms which capture the interrelationship between both critic and word-of-mouth valence and other signals of quality available to buyers, which allow for the formal testing of hypothesis $\mathrm{H}_{3}$. We find evidence to suggest that some degree of interaction is important in explaining variations in sales performance, especially between the valence of professional critics and a mature age rating. The signs and relative magnitudes of the coefficients suggest that opinions of professional critics associate more strongly with sales performance for games with a mature rating. Mature titles that are suggested to be of poor quality sell significantly fewer units on average, while mature titles which are suggested to be of high quality by professional critics perform disproportionately strongly. This suggests that adult consumers of video games may be more discerning with regards to product quality than younger consumers, since the sales of titles rated for a general or teen audience do not seem to associate as strongly with stronger sales performance. There is also limited evidence of a significant interaction between sequels and the valence of both critics and users, although the effect is clearly not as strong. Although we would naturally expect to observe smaller coefficient estimates for these interaction terms, the combination of small and insignificant values is somewhat suggestive of diminishing returns to additional information and signals of product quality. Overall, we find some support for hypothesis $\mathrm{H}_{3}$ to the extent that only the interaction of specific combinations of signals (most notably between critic valence and age rating) explains significant variations in sales performance.

These findings suggest that video game consumers generally make purchasing decisions based upon multiple reliable indicators of quality, such that disproportionately greater sales tend to be observed where a two or more credible signals are observed together. This is reinforced by observing that the individual coefficients for valence of user and professional critics are themselves statistically insignificant in these regressions; only the interaction of valence and other signals of quality appears to explain variation in sales performance. A further point to note is that the two information criteria (AIC and BIC) used to select the preferred model specification suggest some uncertainty with regards to interaction terms and whether their inclusion improves the modelling. The AIC suggests model V (with interaction terms) is the preferred specification, whereas the BIC suggests specification III (without interaction terms). However, the preferred model excluding interaction terms is the specification that includes both reviews from professional critics and consumer word-of-mouth, whereas the preferred specification including interaction terms features only interactions between reviews from professional critics and other observable signals of quality. It is therefore clear that it seems to be more important to capture interactions with reviews from 
professional critics than any other variable.

A possible concern over the results presented and discussed above relates to the potential for endogeneity between the variables of most significant interest; namely between sales performance and professional critical valence. Following the theory of Eliashberg and Shugan (1997), it can be argued that reviews from professional critics simply predict rather than influence sales. If this is true, it is possible that any positive association observed between the two simply reflects correlation as opposed to causality. To respond to this concern, we also produce a series of Generalized Method of Moments (GMM) regressions to control for endogeneity using an instrument for the valence of professional critics. Although it is difficult to identify suitable instruments within our dataset, we propose the use of consumer valence as a possible candidate. In some respects, this is consistent with the modelling approach adopted by Chintagunta et al. (2010), who use reviews from professional critics as an instrument to control for endogeneity in their observed relationship between consumer word-of-mouth and commercial success. In the context of the results presented above and the estimated relationships between reviews from professional critics, users and sales performance in the market for video games, it seems appropriate to model the relationships in this way; indeed, consumer valence seems to meet all of the necessary criteria for inclusion as an instrumental variable. We have already seen that the coefficient estimates for consumer valence estimated in the OLS regressions become statistically insignificant once professional critic valence is separately controlled for. Additionally, we have demonstrated how consumer word-of-mouth is correlated with professional critic valence, but has less than half the strength of correlation with sales compared to professional critic reviews (see Table 2). A number of other authors have also noted the lack of strong, direct association between word-of-mouth valence and sales figures, including Liu (2006) and Duan et al. (2008), who both show that the majority of the explanatory power comes from the volume of online user reviews rather than the valence. An auxiliary regression confirms the strength of consumer word-of-mouth as an instrument for professional critic valence, with $\mathrm{F}$ statistics ranging between 35.80 and 71.04 (depending on the inclusion/ exclusion of the volume and consistency of reviews from professional critics); all well in excess of the recommended minimum value of 10 . The evidence we have therefore suggests that user valence is likely to be a suitable instrument to control for the endogenous nature of the relationship between sales performance and reviews from professional critics.

[Table 4 about here]

Even after controlling for endogeneity between valence of professional critics and sales performance in 
this way, our results remain relatively consistent compared with the OLS regression output. In model specification VIII, we see that in isolation, professional critic valence continues to demonstrate has a positive and significant influence upon sales performance. However, once other measures of response from professional critics and interactions with other signals are taken into account in specifications IX$\mathrm{XI}$, this effect either diminishes or becomes indistinguishable from zero. These results therefore also reinforce the finding that the interaction between reviews from professional critics and a mature age rating is able to explain a significant amount of variation in sales performance. Other control variables show essentially identical relationships with sales as outlined previously, even after taking into account the endogeneity between the two key variables of interest.

In summary, our empirical findings show partial support for our original research hypothesis $\mathrm{H}_{1}$. The predicted relationship with sales performance is observed strongly in the case of professional critics and although we find evidence that a strong association between sales and consumer valence in isolation, the effect disappears once reviews from professional critics and other signals of product quality are controlled for. We also find partial support for hypothesis $\mathrm{H}_{3}$, given that our regressions show significant interaction effects exist between certain key combinations of signals. Finally, we reject hypothesis $\mathrm{H}_{2}$ relating to the importance of interaction between reviews from professional critics and consumer word-of-mouth, finding no evidence to support the prediction that video game consumers attach a value to the presence of both of these signals simultaneously.

Overall, this leads us to conclude that reviews from professional critics generally have a greater effect on buyer behavior than consumer word-of-mouth in the market for video games software. This is somewhat surprising given that the existing literature on word-of-mouth advertising consistently finds evidence of a significant influence upon sales, although in most cases such studies fail to simultaneously control for the influence of interaction with reviews from professional critics. However, we consider this finding to be entirely plausible given the timing of the availability of these signals, with reviews from professional critics typically being available to consumers some time in advance of the product release date, whereas wordof-mouth exchange between consumers are essentially only possible post-release. This disparity, as well as results from our GMM estimations, leads us to conclude that professional critics do seem to have an influencing effect on sales that outweighs consumer word-of-mouth. However, our results also suggest that the interaction between professional critic valence and other externally observable signals of product quality associates significantly with sales performance; this is especially true for the interaction between professional critic valence and mature age ratings, as to some extent with sequels. The former finding in 
particular suggests that the influencing effect of professional critics is even more pronounced for games intended for an adult audience compared with those titles aimed at a younger audience. This suggests that older video game consumers are somewhat more discerning in their choice of titles and that gamers generally are influenced by multiple signals of product quality when they make purchasing decisions.

\section{Concluding remarks and managerial implications}

This study aims to establish the extent to which reviews from professional critics and consumer word-ofmouth affect sales performance in the market for video games. As well as exploring the effects of these two signals of product quality separately, we also estimate their relationship with sales jointly and through interactions between these and other signals of product quality. The findings of this study reinforce the hypothesis that the reviews of professional critics associate strongly with commercial success. After taking steps to control for endogeneity through the use of a GMM estimator, we find evidence that reviews from professional critics, in concert with other observable signals of product quality, influence sales as opposed to merely predicting them, suggesting that their independence and reputation serves as a credible signal that helps consumers to support the decision making process by minimizing uncertainty. We also find only limited evidence to suggest that the valence of consumer-word-of-mouth affects product sales once we control for reviews from professional critics and interaction terms. Consequently, our results are somewhat counterintuitive to a commonly held belief in the value of consumer word-of-mouth and emphasize the greater importance of reviews from professional critics in this particular market context.

In terms of placing our study and our findings within the context of the extant literature, it is clear that our results reinforce some well-established findings, while presenting alternative and sometimes contradictory evidence on others. The only other prior study that has focused on the market for video games is by Zhu and Zhang (2010), who fail to control for the reviews from professional critics alongside their measure of consumer word-of-mouth and even explicitly mention the inclusion of such controls as a worthwhile extension of their work. Hence, our study is able to improve through the inclusion of a greater number of control variables compared with theirs. However, our findings contradict a number of similar studies undertaken on the movie industry. For example, the study by Moon et al. (2010) finds evidence of significant interaction between the valence of users and professional critics, whereas we find no such evidence in the market for video games. Perhaps this difference in findings relates to heterogeneous consumer behavior in the respective markets, with movie consumers appearing to place a 
higher value on universal acclaim among both critics and users compared with the video games consumers, who seemingly attach a higher value on reviews from professional critics.

We also arrive at contradictory results in comparison with Chintagunta et al. (2010), given that they highlight the importance of the valence of word-of-mouth and find no evidence for significant explanatory power of reviews from professional critics, nor the volume and valence of user reviews. We essentially arrive at the opposite conclusions, potentially as a consequence of our aggregation to the national level versus their regional-level analysis; an acknowledgment the authors themselves make in their paper. Instead, our findings are perhaps in most accordance with the recent study by Basuroy et al. (2014), who also highlight the importance of controlling for both reviews from critics and consumer word-of-mouth simultaneously. They find that the strength of relationship between sales and either form of review diminishes once the other is controlled for. However, our findings differ in the sense that they again find evidence of significant interaction between the two measures, whereas our findings suggest otherwise. Nonetheless, this recent study highlights an increasing awareness on the part of researchers into entertainment markets to properly control for both reviews from professional critics and consumer wordof-mouth when attempting to model sales performance, as well as possible interactions between them and a range of other signals of product quality.

From a managerial perspective, it is of vital importance to forecast product sales efficiently, in particular those of new products in the early stages of their life cycle. Thus, it is important to understand the range of relevant signals that influence the behaviour of customers and how the information contained in these signals can be measured and evaluated in order to optimize managerial decisions and strengthen competitive advantages. Our results also suggest that measures of valence from professional critics, such as Metacritic scores, are of vital importance to video games developers and publishers. We therefore also suggest that publishers should make increasing use of contracts with development studios whereby royalties are paid or received based on the critical response achieved by a given title, as this is shown to be a major factor in determining sales performance. This is a particularly important recommendation for titles designed for a mature audience, since it appears that the opinions of professional critics carry even more weight among this particular market segment and hence exert an even greater influence on commercial performance. 


\section{References}

Archak N, Ghose A, \& Ipeirotis PG. (2011). Deriving the pricing power of product features by mining consumer reviews. Management Science 57(8): 1485-1509.

Basuroy S, Chatterjee S, \& Ravid S.A. (2003). How critical are critical reviews? The box office effects of film critics, star power and budgets. Journal of Marketing 67(4): 103-117.

Basuroy S, Desai K.K, \& Talukdar D. (2006). An Empirical Investigation of Signaling in the Motion Picture Industry. Journal of Marketing Research 43(2): 287-295.

Basuroy, S. \& Chatterjee, S. (2008). Fast and frequent: Investigating box office revenues of motion picture sequels. Journal of Business Research, 61(7), 798-803.

Basuroy, S., Rao, V. R., \& Ravid, S. A. (2011). What is advertising content worth? Evidence from the motion pictures industry. Evidence from the Motion Pictures Industry. Johnson School Research Paper, (45-2011).

Basuroy, S., Ravid, S.A.A., \& Hall, B. (2014). How Relevant Are Experts In The Internet Age? Evidence from the Motion Pictures Industry? Working Paper, University of Oklahoma

Boatwright P, Basuroy S, Kamakura W. (2007). Reviewing the reviewers: The impact of individual film critics on box office performance. Quantitative Marketing and Economics 5(4): 401-425.

Bughin, J., Doogan, J., \& Vetvik, O. J. (2010). A new way to measure word-of-mouth marketing. McKinsey Quarterly, 2, 113-116.

Chakravarty, A., Liu, Y., \& Mazumdar, T. (2010). The differential effects of online word-of-mouth and critics' reviews on pre-release movie evaluation. Journal of Interactive Marketing, 24(3), 185-197.

Chen Y, Xie J. (2008). Online Consumer Review: Word-of-Mouth as a New Element of Marketing Communication Mix. Management Science 54(3): 477-491.

Chevalier JA, Mayzlin D. (2006). The effect of word-of-mouth on sales: Online book reviews. Journal of Marketing Research 43(3): 345-354.

Chintagunta P, Gopinath S, Venkataraman S. (2010). The effects of online word-of-mouth reviews on movie box office performance: Accounting for sequential rollout and aggregation across local markets. Marketing Science, 29(5): 944-957.

Clemons EK, Gao G, Hitt L. (2006). When online review meets hyperdifferentiation: a study of the craft beer industry. Journal of Management Information Systems 23(2): 149-171.

Cox J. (2013). What makes a blockbuster video game? An empirical analysis of US sales data. Managerial and Decision Economics, 35(3): 189-198.

Cui G, Lui HK, Guo X. (2012). The Effect of Online Consumer Reviews on New Product Sales. International Journal of Electronic Commerce 17(3): 39-57. 
Dellarocas C. (2003). The Digitization of Word-of-mouth: Promise and Challenges of Online Feedback Mechanisms. Management Science 49(10): 1407-1424.

Dellarocas C, Zhang X, Awad N.F. (2007). Exploring the value of online product reviews in forecasting sales: The case of motion pictures. Journal of Interactive Marketing 21(4): 23-45.

De Vany A, Walls W.D. (2002). Does Hollywood make too many R-Rated Movies? Risk, Stochastic Dominance, and the Illusion of Expectation. Journal of Business, 75(3): 425-451.

Dhar, T., Sun, G., \& Weinberg, C.B. (2012). The long-term box office performance of sequel movies. Marketing Letters, 23(1), 13-29.

Duan W, Gu B, Whinston AB. (2008). Do online reviews matter? An empirical investigation of panel data. Decision Support Systems, 45(4): 1007-1016.

Elberse, A., \& Eliashberg, J. (2003). Demand and supply dynamics for sequentially released products in international markets: The case of motion pictures. Marketing Science, 22(3), 329-354.

Eliashberg J, Shugan S.M. (1997). Film Critics. Influencers or Predictors? Journal of Marketing, 61(2): 68-78.

Entertainment Software Association. (2012). Essential facts about the computer and video games industry. Available at http://www.theesa.com/facts/pdfs/ESA_EF_2012.pdf

Fahlenbrach, R., \& Stulz, R.M. (2011). Bank CEO incentives and the credit crisis. Journal of Financial Economics, 99(1), 11-26.

Fama, E.F. (1980). Agency Problems and the Theory of the Firm. Journal of Political Economy, 288-307.

Gemser, G., Van Oostrum, M., \& Leenders, M. A. (2007). The impact of film reviews on the box office performance of art house versus mainstream motion pictures. Journal of Cultural Economics, 31(1), 43-63.

Godes D, Mayzlin D. (2004). Using online conversation to study word-of-mouth communication. Marketing Science, 23(4): 545-560.

Hennig-Thurau, T., Marchand, A., Hiller, B. (2012). The relationship between reviewer judgments and motion picture success: re-analysis and extension. Journal of Cultural Economics, 36(3), 249-283.

Hennig-Thurau, T., Wiertz, C., \& Feldhaus, F. (2014). Does Twitter matter? The impact of microblogging word-of-mouth on consumers' adoption of new movies. Journal of the Academy of Marketing Science, 1-20.

Hölmstrom, B. (1979). Moral hazard and observability. The Bell Journal of Economics, 74-91.

Jensen, M. C., \& Murphy, K. J. (1990). Performance pay and top-management incentives. Journal of Political Economy, 225-264.

Kirmani A, Rao A.R. (2000). No pain, no gain: A critical review of the literature of signaling unobservable product quality. Journal of Marketing 64(2): 66-79.

Holbrook, M. B., \& Addis, M. (2007). Taste versus the market: An extension of research on the consumption of popular culture. Journal of Consumer Research, 34(3), 415-424. 
Litman B.R. (1983). Predicting Success of Theatrical Movies. An Empirical Study. Journal of Popular Culture 16(4): 159-175.

Liu Y. (2006). Word-of-Mouth for Movies: Its Dynamics and Impact on Box Office Revenue. Journal of Marketing, 70(3): 74-89.

Moon S, Bergey P, Iacobucci D. (2010). Dynamic effects among movie ratings, movie revenues, and viewer satisfactions. Journal of Marketing 74(1): 108-121.

Nelson P. (1970). Information and Consumer Behavior. Journal of Political Economy, 78(2): 311-329.

Prag, J., \& Casavant, J. (1994). An empirical study of the determinants of revenues and marketing expenditures in the motion picture industry. Journal of Cultural Economics, 18(3), 217-235.

Racherla P, Mandviwalla M, Connolly DJ. (2012). Factors affecting consumers' trust in online product reviews. Journal of Consumer Behaviour, 11(2): 94-104.

Ravid AS. (1999). Information, Blockbusters and Stars. A Study of the Film Industry. Journal of Business 72(4): 463-492.

Roschk, H., \& GroßE, S. (2013). Talking about films: Word-of-mouth behavior and the network of success determinants of motion pictures. Journal of Promotion Management, 19(3), 299-316.

Schindler RM, Bickart B. (2012). Perceived helpfulness of online consumer reviews: The role of message content and style. Journal of Consumer Behaviour 11(3): 234-243.

Senecal S, Nantel J. (2004). The influence of online product recommendations on consumers' online choices. Journal of Retailing 80(2): 159-169.

Sochay S. (1994). Predicting the Performance of Motion Pictures. Journal of Media Economics 7(4): 1-20.

Spence M. (1973). Job Market Signaling. Quarterly Journal of Economics 87(3): 355-374.

Terry, N., Butler, M., \& De’Armond, D.A. (2011). The determinants of domestic box office performance in the motion picture industry. South-western Economic Review, 32, 137-148.

Weimann G. (1991). The Influentials: Back to the Concept of Opinion Leaders. Public Opinion Quarterly 55(2): 267-279.

Wien A.H, Olsen S.O. 2012. Evaluation context's role in driving positive word-of-mouth intentions. Journal of Consumer Behaviour, 11(6): 504-513.

Wingfield N. (2007). High Scores Matter To Game Makers, Too. Available at http://online.wsj.com/public/article/ SB119024844874433247EnpxM1F6fI9YZDofC7VnyPzVrGQ_20070920.html

Zhu F, Zhang X. (2010). Impact of online consumer reviews on sales: The moderating role of product and consumer characteristics. Journal of Marketing 74(2): 133-148. 
Figures and Tables

Figure 1: US Video Games Market Development from 1995 to 2012

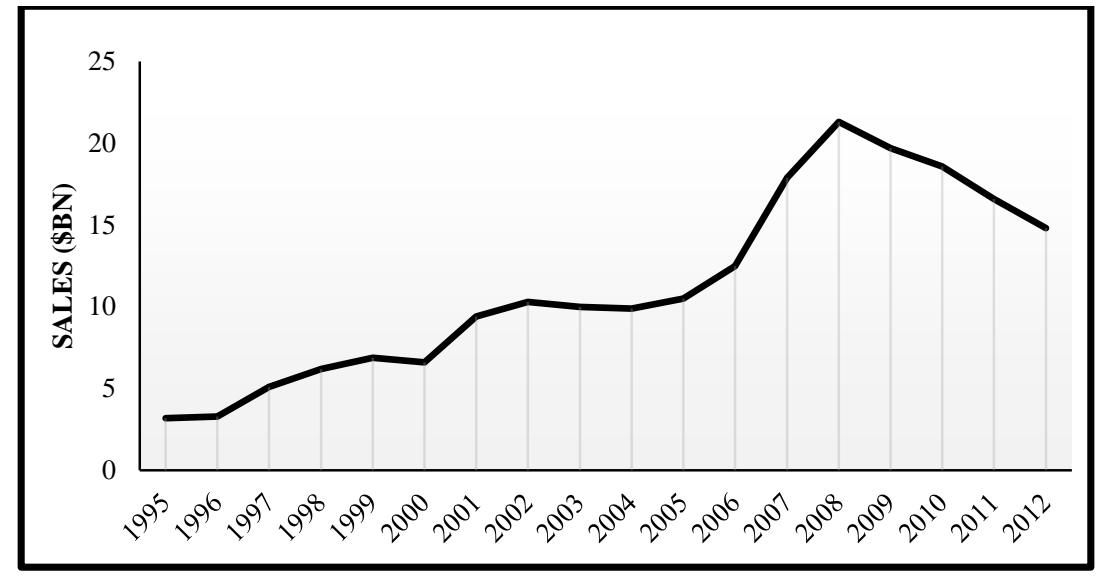

Figure 2: Lorenz Curve of Consistency Measures

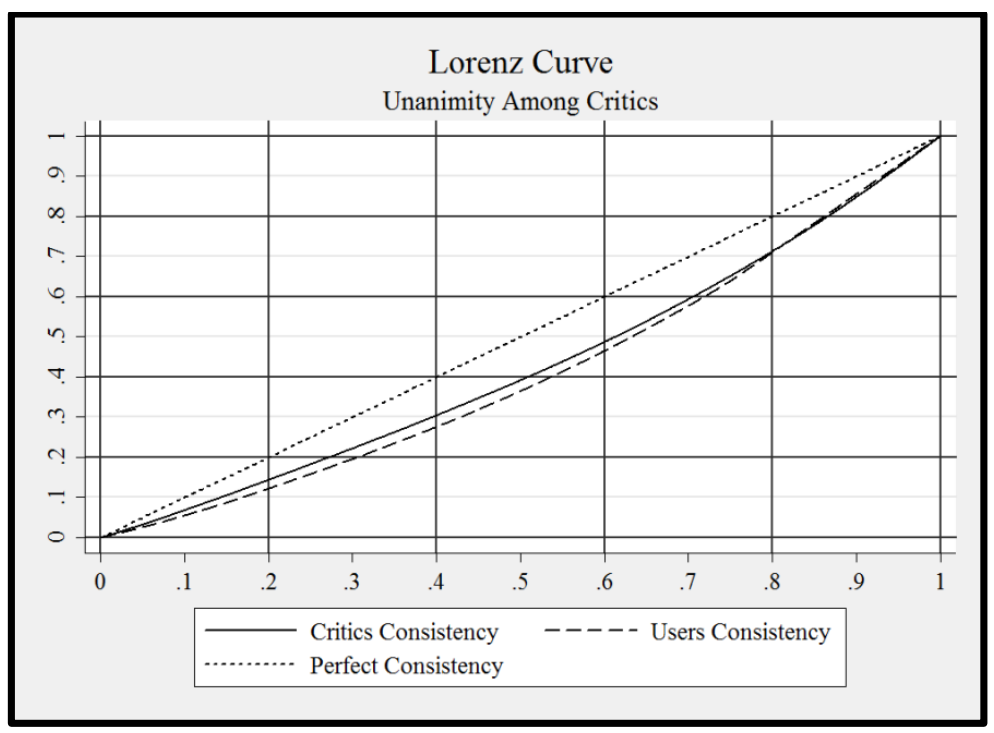




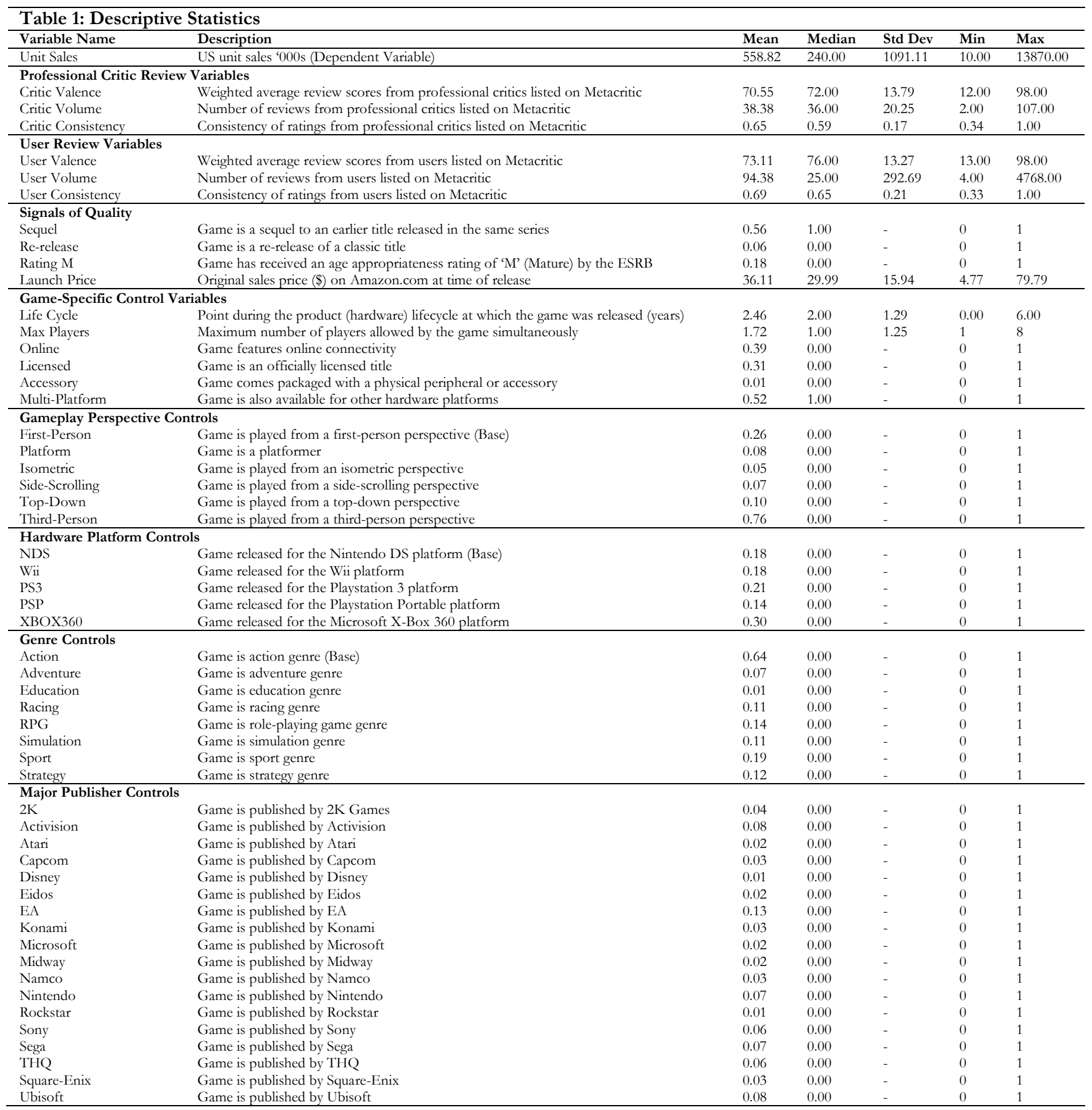


Table 2: Correlation Coefficients

\begin{tabular}{|c|c|c|c|c|c|c|c|}
\hline & Critic Valence & Critic Volume & Critic Consistency & User Valence & User Volume & User Consistency & US Sales \\
\hline Critic Valence & 1.00 & 0.53 & 0.49 & 0.63 & 0.33 & 0.11 & 0.33 \\
\hline Critic Volume & 0.53 & 1.00 & 0.29 & 0.27 & 0.48 & -0.12 & 0.35 \\
\hline Critic Consistency & 0.49 & 0.29 & 1.00 & 0.22 & 0.35 & 0.12 & 0.32 \\
\hline User Valence & 0.63 & 0.27 & 0.22 & 1.00 & 0.10 & 0.35 & 0.13 \\
\hline User Volume & 0.33 & 0.48 & 0.35 & 0.10 & 1.00 & -0.05 & 0.44 \\
\hline User Consistency & 0.11 & -0.12 & 0.12 & 0.35 & -0.05 & 1.00 & -0.06 \\
\hline US Sales & 0.33 & 0.35 & 0.32 & 0.13 & 0.44 & -0.06 & 1.00 \\
\hline
\end{tabular}


Table 3: OLS Regression Results

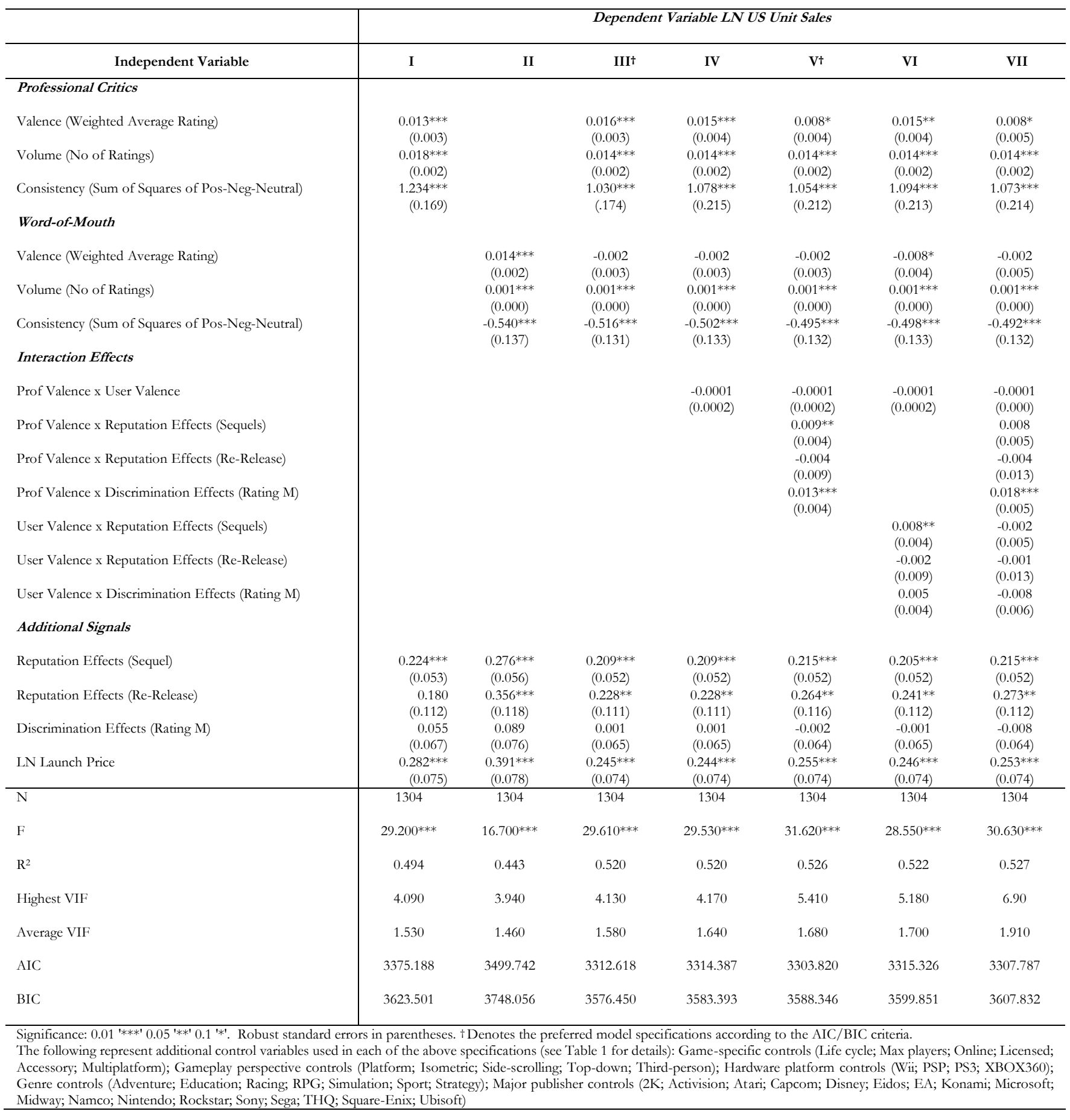


Table 4: GMM Regression Results (Instrument: User Valence)

\begin{tabular}{|c|c|c|c|c|}
\hline \multirow[b]{2}{*}{ Independent Variable } & \multicolumn{4}{|c|}{ Dependent Variable LN US Unit Sales } \\
\hline & VIII & IX & $\mathbf{x}$ & XI \\
\hline \multicolumn{5}{|l|}{ Professional Critics } \\
\hline Valence (Weighted Average Rating) & $\begin{array}{c}0.021^{* * *} \\
(0.004)\end{array}$ & $\begin{array}{c}0.004 \\
(0.005)\end{array}$ & $\begin{array}{c}0.012^{* * *} \\
(0.005)\end{array}$ & $\begin{array}{c}0.005 \\
(0.006)\end{array}$ \\
\hline Volume (No of Ratings) & & $\begin{array}{c}0.021 * * * \\
(0.002)\end{array}$ & $\begin{array}{c}0.015^{* * *} \\
(0.002)\end{array}$ & $\begin{array}{c}0.014^{* * *} \\
(0.002)\end{array}$ \\
\hline Consistency (Sum of Squares of Pos-Neg-Neutral) & & $\begin{array}{c}1.442 * * * \\
(0.195)\end{array}$ & $\begin{array}{c}1.095^{* * *} \\
(0.192)\end{array}$ & $\begin{array}{c}1.033^{* * *} \\
(0.178)\end{array}$ \\
\hline \multicolumn{5}{|l|}{ Word-of-Mouth } \\
\hline Volume (No of Ratings) & & & $\begin{array}{c}0.001 * * * \\
(0.000)\end{array}$ & $\begin{array}{c}0.001 * * * \\
(0.000)\end{array}$ \\
\hline Consistency (Sum of Squares of Pos-Neg-Neutral) & & & $\begin{array}{c}-0.521 * * * \\
(0.126)\end{array}$ & $\begin{array}{c}-0.516^{* * *} \\
(0.125)\end{array}$ \\
\hline \multicolumn{5}{|l|}{ Interaction Effects } \\
\hline Prof Valence x Reputation Effects (Sequels) & & & & $\begin{array}{l}0.010^{* *} \\
(0.005)\end{array}$ \\
\hline Prof Valence x Reputation Effects (Re-Release) & & & & $\begin{array}{l}-0.003 \\
(0.009)\end{array}$ \\
\hline Prof Valence x Discrimination Effects (Rating M) & & & & $\begin{array}{c}0.014 * * * \\
(0.004)\end{array}$ \\
\hline \multicolumn{5}{|l|}{ Additional Signals } \\
\hline Reputation Effects (Sequel) & $\begin{array}{c}0.222^{* * *} \\
(0.057)\end{array}$ & $\begin{array}{c}0.250^{* * *} \\
(0.054)\end{array}$ & $\begin{array}{c}0.219^{* * *} \\
(0.053)\end{array}$ & $\begin{array}{c}0.224 * * * \\
(0.053)\end{array}$ \\
\hline Reputation Effects (Re-Release) & $\begin{array}{l}0.223^{*} \\
(0.118)\end{array}$ & $\begin{array}{l}0.209^{*} \\
(0.108)\end{array}$ & $\begin{array}{c}0.237 * * \\
(0.108)\end{array}$ & $\begin{array}{c}0.270^{* *} \\
(0.113)\end{array}$ \\
\hline Discrimination Effects (Rating M) & $\begin{array}{c}0.193^{* * *} \\
(0.075)\end{array}$ & $\begin{array}{c}0.047 \\
(0.066)\end{array}$ & $\begin{array}{l}-0.001 \\
(0.064)\end{array}$ & $\begin{array}{l}-0.003 \\
(0.063)\end{array}$ \\
\hline LN Launch Price & $\begin{array}{c}0.454^{* * *} \\
(0.078) \\
\end{array}$ & $\begin{array}{c}0.311 * * * \\
(0.076) \\
\end{array}$ & $\begin{array}{c}0.249 * * * \\
(0.073) \\
\end{array}$ & $\begin{array}{c}0.260^{* * *} \\
(0.073) \\
\end{array}$ \\
\hline $\mathrm{N}$ & 1304 & 1304 & 1304 & 1304 \\
\hline Wald Chi2 & $748.80^{* * *}$ & $1408.80^{* * *}$ & $1526.10^{* * *}$ & $1773.34^{* * *}$ \\
\hline $\mathrm{R}^{2}$ & 0.426 & 0.489 & 0.519 & 0.525 \\
\hline
\end{tabular}

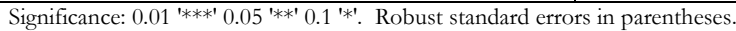

The following represent additional control variables used in each of the above specifications (see Table 1 for details): Game-specific controls (Life cycle; Max players; Online; Licensed; Accessory; Multiplatform); Gameplay perspective controls (Platform; Isometric; Side-scrolling; Top-down; Third-person);

Hardware platform controls (Wii; PSP; PS3; XBOX360); Genre controls (Adventure; Education; Racing; RPG; Simulation; Sport; Strategy); Major publisher controls (2K; Activision; Atari; Capcom; Disney; Eidos; EA; Konami; Microsoft; Midway; Namco; Nintendo; Rockstar; Sony; Sega; THQ; Square-Enix; Ubisoft) 